\title{
On the Spinal Root Pathway of the Adrenaline- Secretory Fibers to the Adrenal Gland in Toads
}

\author{
By \\ Masaaki Inoue \\ (井上 公明) \\ From the Department of Physiology, Nagasaki University \\ School of Medicine, Nagasaki
}

(Received for publication, July 10, 1958)

The pathway of the adrenaline-secretory fibers to the adrenal gland in mammals has been studied by many investigators. We are, however, fully unaware of that in cold blooded animals such as frogs and toads.

In my previous study ${ }^{1}$ it was observed that the marked depletion of the adrenaline content of the adrenal gland in toads was producible by insulin hypoglycemia and this depletion was abolished by the previous section of the splanchnic nerves in the corresponding side. These experimental results indicate that the adrenaline-secretory fibers to the adrenal run in the splanchnic nerves.

The present investigation was undertaken to determine the spinal roots through which the adrenaline-secretory fibers course, by measuring the effect of the ventral or dorsal spinal roots sections at various levels of spinal segments on the decrease in the adrenaline content of the adrenal gland causable by insulin hypoglycemia.

\section{EXPERIMENTAL \\ Methods}

Male and female toads were used. All the experimental procedures were almost the same as those of my previous investigation. ${ }^{1)}$ The spinal roots were laid bare by opening the dura and were sectioned on the left side. Insulin was injected in a dose of 15 units per $\mathrm{kg}$. of body weight. This dose of insulin was found in my previous study to be sufficient for depleting the adrenaline content of the adrenal gland with intact innervation in toads. Since it was proved that the adrenaline content of the splanchnicotomized gland was not influenced by insulin hypoglycemia, the splanchnic nerves were cut on the right side and the adrenaline content of the right gland was taken as the control for comparison. The adrenaline and noradrenaline contents of the gland were estimated by the use of the permanganate method of Suzuki and Ozaki. ${ }^{2)}$ 


\section{Results}

In 7 toads the 3 rd -7 th dorsal and ventral spinal roots were cut on the left side. The splanchnic nerves were severed on the right side. After 6 days subcutaneous injection of insulin was made and at 10 hours after insulin the adrenaline and noradrenaline contents were estimated.

The adrenaline content of the adrenal gland, computed per $\mathrm{kg}$. of body weight, was $0.182(0.142-0.215) \mathrm{mg}$. and $0.188(0.142-0.218) \mathrm{mg}$. in the left and the right gland, respectively. That of noradrenaline was estimated as $0.144(0.120-0.175) \mathrm{mg}$. and $0.149(0.108-0.182) \mathrm{mg}$. in the left and the right gland, respectively. There was no significant difference between the estimates of the left and the right gland $(P>0.25)$. Thus the decrease in the adrenaline content producible by insulin was proved to be fully prevented by the section of the 3rd-7th dorsal and ventral spinal roots.

In 5 toads the left 3 rd -7 th dorsal spinal roots and the right splanchnic nerves were cut. Six days after the nerve sections the injection of insulin was made.

The adrenaline content per kg. of body weight in the left adrenal gland was measured as $0.107(0.090-0.130) \mathrm{mg}$. and that of in the left gland as $0.208(0.155-0.280) \mathrm{mg}$. The noradrenaline content per $\mathrm{kg}$. of body weight was $0.114(0.077-0.162) \mathrm{mg}$. and $0.118(0.080-0.160) \mathrm{mg}$. in the left and the right adrenal gland, respectively. The difference between the estimates of adrenaline content of the left and the right adrenal gland was statistically highly significant $(P<0.001)$, indicating that the decrease in the adrenaline content of the adrenal gland producible by insulin hypoglycemia cannot be prevented by the 3 rd -7 th dorsal spinal roots section.

Eight toads were experimented on. On the right side, the splanchnic nerves were cut. On the left side, the 3 rd-7th ventral spinal roots were severed. After 6 days the application of insulin was performed.

The adrenaline content per $\mathrm{kg}$. of body weight in the left gland was estimated as $0.179(0.138-0.270) \mathrm{mg}$. and that in the left gland was $0.180(0.145-0.274) \mathrm{mg}$. The noradrenaline content per kg. was 0.096 $(0.073-0.126) \mathrm{mg}$. in the left gland and $0.094(0.061-0.133) \mathrm{mg}$. in the right gland. Difference between adrenaline estimates in the left and the right glands was statistically not significant $(P>0.20)$. The depletion of adrenaline content in the adrenal gland causable by insulin hypoglycemia was able to be prevented by the previous section of the 3rd-7th ventral 
spinal roots.

Five groups of animals were used. The splanchnic nerves were cut on the right side. Four ventral spinal roots out of five (the 3rd-7th) were severed on the left side, only one root being remained intact. Insulin was given 6 days after nerve sections.

Group $A$. In 8 toads the 3 rd ventral spinal root was remained intact and the other 4 roots were cut. The adrenaline content of the left adrenal gland per kg. of body weight was estimated as $0.138(0.062-0.186) \mathrm{mg}$. and that of the right gland was $0.204(0.130-0.260) \mathrm{mg}$. The difference of estimates was statistically highly significant $(P<0.001)$. The noradrenaline content per kg. was $0.141(0.110-0.181) \mathrm{mg}$. and $0.146(0.100-0.193) \mathrm{mg}$. in the left and right gland, respectively.

Group B. In 7 toads the $3 \mathrm{rd}$, the 5 th, the 6 th, and the 7 th ventral spinal roots were cut, leaving the 4 th root intact. The adrenaline content per kg. was $0.127(0.068-0.170) \mathrm{mg}$. in the left gland and $0.227(0.176-$ $0.270) \mathrm{mg}$. in the right gland. The difference was highly significant $(\mathrm{P}<0.001)$. The noradrenaline content per kg. was $0.146(0.106-0.178)$ mg. and $0.149(0.112-0.185) \mathrm{mg}$. in the left and the right gland, respectively.

Group C. Six toads were experimented on. The 5th ventral spinal root was kept intact and the other 4 roots were severed. The adrenaline content per kg. was $0.127(0.069-0.197) \mathrm{mg}$. in the left adrenal gland and $0.208(0.150-0.268) \mathrm{mg}$. in the right gland, respectively. The difference was statistically highly significant $(\mathbf{P}<0.005)$. The noradrenaline content per $\mathrm{kg}$. of body weight was $0.124(0.102-0.142) \mathrm{mg}$. and $0.133(0.102-$ $0.155) \mathrm{mg}$. in the left and the right gland, respectively.

Group $D$. Experiments were performed in 8 toads. The 3rd, the 4 th, the 5 th and the 7 th ventral spinal roots were sectioned, leaving the 6 th root intact. The adrenaline content per $\mathrm{kg}$. in the left adrenal gland was $0.205(0.158-0.305) \mathrm{mg}$. and that in the right gland was $0.207(0.164$ $0.285) \mathrm{mg}$. There was no significant difference between the estimates $(\mathrm{P}>0.50)$. The noradrenaline content was $0.131(0.089-0.149) \mathrm{mg}$. and $0.128(0.095-0.144) \mathrm{mg}$. in the left and the right adrenal gland, respectively.

Group E. Eight toads were employed. The 3rd-6th ventral spinal roots were cut and the 7 th root was kept intact. The adrenaline content per $\mathrm{kg}$. of body weight was estimated as $0.180(0.145-0.246) \mathrm{mg}$. in the left gland and as $0.183(0.146-0.239) \mathrm{mg}$. in the right gland. There was no significant difference between the estimates $(P>0.50)$. The noradrenaline content per $\mathrm{kg}$. was $0.104(0.068-0.129) \mathrm{mg}$. an $0.101(0.077-$ 
$0.130) \mathrm{mg}$. in the left and the right adrenal gland, respectively.

By these experiments it was proved that the depletion in the adrenaline content of the adrenal gland causable by insulin hypoglycemia was not be prevented by the ventral spinal roots sections, if the 3rd, the 4th or the 5 th root was remained intact. In contrast, the integrity of the 6 th or the 7 th ventral spinal root was found to have no effect on the prevention by the ventral root sections of the adrenaline depletion.

In 9 toads the $3 \mathrm{rd}$, the 4 th and the 5 th ventral spinal roots were cut on the left side and the splanchnic nerves were sectioned on the right side. Six days after nerve sections the injection of insulin was made.

The adrenaline content, computed per kg. of body weight, was 0.165 (0.141-0.187) $\mathrm{mg}$. and $0.167(0.143-0.193) \mathrm{mg}$. in the right and the left adrenal gland, respectively. No significant difference was found between the estimates $(\mathrm{P}>0.50)$. The noradrenaline content per kg. was 0.095 (0.059-0.129) mg. and $0.098(0.066-0.126) \mathrm{mg}$., respectively.

The results showed that the depletion of the adrenaline content of the adrenal gland producible by insulin hypoglycemia could be fully prevented by the sections of the 3 rd -5 th ventral spinal roots.

\section{Discussion}

In my previous work it was demonstrated that the adrenaline content of the adrenal gland in toads was decreased by insulin hypoglycemia and the section of the splanchnic nerves was capable of preventing the depletion of adrenaline content. These results indicated that the adrenalinesecretory fibers to the adrenal gland ran through the splanchnic nerves.

In the present investigation it was found at first that the decrease in the adrenaline content of the adrenal gland producible by insulin hypoglycemia was fully abolished by the 3rd-7th ventral and dorsal spinal roots section. The adrenaline-secretory fibers were thus proved to leave the spinal cord and run in some of these spinal roots. In the next step, the 3 rd-7th ventral spinal roots section was made in one group of animals and the 3rd-7th dorsal spinal roots section in the other. The former was found to prevent the adrenaline depletion causable by insulin hypoglycemia, whereas the latter to have no effects in preventing the adrenaline depletion. Thus the adrenaline-secretory fibers were proved to run through some of these ventral spinal roots.

Then, further experiments were performed to decide the ventral spinal roots through which the adrenaline-secretory fibers run. When the 3rd ventral spinal root only was kept intact and the other 4 ventral roots, i.e. the 4 th, the 5 th, the 6 th and the 7 th, were cut, the depletion 
of adrenaline content due to insulin hypoglycemia was not prevented by such nerve sections. The same was true, when the 4 th or the 5 th ventral spinal root only was left intact. On the other hand, when the 6th or the 7 th ventral spinal root was kept intact and the other 4 roots were cut, the decrease in the adrenaline content producible by insulin hypoglycemia was entirely nullified. The section of the $3 \mathrm{rd}$, the 4 th and the 5 th ventral spinal roots was found to be enough to prevent the adrenaline depletion in the adrenal gland causable by insulin hypoglycemia. Thus it is justifiable to conclude that the adrenaline-secretory fibers in toads run through the $3 \mathrm{rd}$, the 4 th and 5 th ventral spinal roots.

As to the adrenaline-secretory fibers to the adrenal gland in dogs, Tournade and his co-workers ${ }^{3)}$ demonstrated that an increase in the adrenaline secretion was produced by the stimulation of $\mathrm{D}_{\mathbf{4}}-\mathrm{L}_{\mathbf{1}}$ ventral spinal roots but not by the centrifugal dorsal spinal root stimulation, indicating that the adrenaline-secretory fibers run through the ventral spinal roots. In cats Young") found histologically that the fibers to the adrenal medulla ran in $D_{6}-D_{16}\left(L_{3}\right)$ ventral spinal roots. In the experiments of Wada et al. $^{5)}$ on unanesthetized dogs, the augmented adrenaline secretion causable by morphine was found to be fully abolished by the section of ventral spinal roots from $\mathrm{D}_{4}$ or $\mathrm{D}_{5}$ to $\mathrm{L}_{3}$ or $\mathrm{L}_{4}$ but not by the dorsal root section.

From the experimental results of above investigators and those of the present investigation it was elucidated that in toads as well as in mammals the adrenaline-secretory fibers to the adrenal gland ran through the ventral spinal roots.

\section{Summary}

In toads the spinal root pathway of the adrenaline-secretory fibers to the adrenal gland was studied, taking the depletion of the adrenal gland as an indicator of augmented adrenaline secretion. The adrenaline and noradrenaline content of the adrenal gland was estimated by the use of the permaganate method.

The adrenaline-secretory fibers were found to run through the 3rd, the 4 th and the 5 th ventral spinal roots.

I wish to thank Prof. T. Suzuki for his help and encouragement, and for reading the manuscript.

\section{References}

1) Inoue, M., Tohoku J. Exp. Med., 1958, 68, 279.

2) Suzuki, T. \& Ozaki, T., ibid., 1951, 54, 332 ; Ozaki, T., ibid., 1954, 61, 83.

3) Tournade, A., Chabrol, M. \& Wagner, P. E., Compt. Rend. Soc. Biol., 1925, 93, 933.

4) Young, J. Z., J. Anat., 1939, 73, 540.

5) Cited in Satake, Y., Tohoku J. Exp. Med., 1954, 60, Suppl. II. 